\title{
Benefits and Consequences for the Poor and the Disabled
}

\section{Citation}

Elliott, Rachel A., Sumit R. Majumdar, Muriel R. Gillick, and Stephen B. Soumerai. 2005.

"Benefits and Consequences for the Poor and the Disabled." New England Journal of Medicine 353 (26) (December 29): 2739-2741. doi:10.1056/nejmp058242.

\section{Published Version}

doi:10.1056/NEJMp058242

\section{Permanent link}

http://nrs.harvard.edu/urn-3:HUL.InstRepos:32692582

\section{Terms of Use}

This article was downloaded from Harvard University's DASH repository, and is made available under the terms and conditions applicable to Other Posted Material, as set forth at http:// nrs.harvard.edu/urn-3:HUL.InstRepos:dash.current.terms-of-use\#LAA

\section{Share Your Story}

The Harvard community has made this article openly available.

Please share how this access benefits you. Submit a story.

\section{Accessibility}


quests for coverage of medications other than those in the formulary can be initiated by the patient or the physician, and plans are supposed to respond within 72 hours (or 24 hours for expedited requests). Appeals are permitted but may be time-consuming. Physicians may also request exceptions to the tiered cost-sharing structure if, for example, their patient cannot tolerate a generic drug. The capacity of many frontline physicians to deliver on these new responsibilities is uncertain, especially given the harried pace and poor reimbursement that are associated with primary care practice. The MMA has no provision for compensating physicians or their office staff for undertaking these activities.

Although there is turbulence ahead, physicians and patients should remember that they are not alone. At last count, the Medicare Web site listed 280 frequently asked questions, and help is available through regional senior health insurance assistance programs and area agencies on aging (www.aoa. gov/eldfam/how_to_find/agencies/ agencies.asp).

The new prescription-drug benefit represents the biggest change in Medicare since its inception in 1965. In the short term, the success of the benefit will hinge on whether patients can successfully negotiate its convoluted options and rules. Over the long haul, the program's viability will depend on whether expenses for prescription drugs can be brought under control. New drug discoveries during the next 10 years promise to deliver remarkable benefits - at startlingly high prices. No doubt the Medicare drug benefit will change over time, and physicians will continue to be called on to help patients traverse the shifting policy landscape safely and successfully.

Dr. Kravitz is a professor of internal medicine and director of the Center for Health Services Research in Primary Care, University of California, Davis; Dr. Chang is the director of the Chronic Care Disease Program, California HealthCare Foundation, Oakland, Calif.

1. Wolf R. Medicare prescription drug plan stumps seniors. USA Today. October 4, 2005:A3.

2. Huskamp HA, Deverka PA, Epstein AM, Epstein RS, McGuigan KA, Frank RG. The effect of incentive-based formularies on prescription-drug utilization and spending. N Engl J Med 2003;349:2224-32.

3. Alexander GC, Casalino LP, Meltzer DO. Physician strategies to reduce patients' outof-pocket prescription costs. Arch Intern Med 2005;165:633-6.

4. Shrank WH, Young HN, Ettner SL, Glassman P, Asch SM, Kravitz RL. Do the incentives in 3-tier pharmaceutical benefit plans operate as intended? Results from a physician leadership survey. Am J Manag Care 2005;11:16-22. [Erratum, Am J Manag Care 2005;11:180.]

MEDICARE DRUG BENEFIT

\title{
Benefits and Consequences for the Poor and the Disabled
}

\author{
Rachel A. Elliott, Ph.D., Sumit R. Majumdar, M.D., M.P.H., Muriel R. Gillick, M.D., and Stephen B. Soumerai, Sc.D.
}

The new Medicare Part D will improve access to medications for millions of Americans. One subgroup of beneficiaries, however, may inadvertently be made worse off: the 7.2 million people enrolled in both Medicaid (because they are poor) and Medicare (because they are elderly or disabled). These beneficiaries, known as the dually eligible, already receive drug benefits through state-run Medicaid programs; but as of 2006, they will be required to enroll in Medicare Part D.

Moving the dually eligible recipients of drug benefits to new federal programs raises several concerns: these beneficiaries may have problems making the transition and negotiating the system; they may discontinue use of essential medications because of increased cost sharing; they may need to switch medications because their new plan offers different coverage from their old one; and they may have difficulty obtaining essential medications because of formulary restrictions.

The dually eligible are poorer and sicker than other Medicare patients (83 percent report fair or poor health vs. 57 percent of those who are not dually eligible), have a higher rate of mental illness or dementia (33 percent vs. 12 percent), are less educated (49 percent have graduated from high school vs. 75 percent), are more likely to be members of minority groups (43 percent vs. 16 percent), and are more likely to live in a nursing home (19 percent vs. 3 percent). ${ }^{1}$ Of the country's 1.6 million nursing-home residents, 70 percent are dually eligible, and most take multiple medications.

Medicare will pay the entire Part D premium for the dually eligible (see table), who will not be required to pay the standard $\$ 250$ deductible, the $\$ 500$ in coinsurance for the first $\$ 2,250$ in drug benefits, or the next $\$ 2,850$ of drug costs. The Center for Medicare and Medicaid Services (CMS) 
began sending letters to dually eligible patients in November, detailing the impending change in their drug coverage and informing them that they will be automatically enrolled in a drug plan if they do not select one by December 31, 2005.

But they were given only six weeks to enroll in a Medicare plan - a selection process that can take several months - despite the fact that this group is especially difficult to reach and to educate about coverage changes. Particularly at risk are the 2.4 million patients with dementia or psychiatric illnesses, who may have difficulty negotiating the system, and patients who move from the community into a nursing home, where they will probably have to select from a whole new set of plans.

Patients who are automatically enrolled in a plan on January 1 and would like to choose a different plan will be permitted to switch. There is no established strategy, however, for moving patients smoothly from one plan to another. Some will be required to switch to different medications covered by the new plan, and some may experience new side effects from new drugs, while others may stop taking their medication altogether.

Before the Medicare Prescription Drug, Improvement, and Modernization Act (MMA) of 2003, the Medicaid prescription-drug benefit provided to the dually eligible was generally comprehensive and involved minimal copayments, except in the 12 states that cap the number of prescriptions allowed (see table). For dually eligible patients who already receive comprehensive drug benefits, the MMA will increase financial barriers and reduce access in most states. These patients will be responsible for copayments of $\$ 1$ to $\$ 2$ for generic drugs and $\$ 3$ to $\$ 5$ for brand-name drugs, instead of the typical copayment of $\$ 3$ or less or even no fee under Medicaid. Medication costs should be reduced for patients living in states with drug caps, if their drug use exceeds the cap. But in other states, it is not clear that costs will be reduced. Patients who are chronically mentally ill are particularly susceptible to increases in copayments that are as low as $\$ 1$.

Although the CMS requires formularies to include "all or substantially all" antidepressant, antipsychotic, anticonvulsant, immunosuppressant, antineoplastic, and antiretroviral agents in 2006, since therapeutic substitution in these classes of drugs is generally inappropriate, this policy will be reevaluated for 2007. The CMS will also require drug plans to fill prescriptions, for an undefined transitional period, for dually eligible nursing-home patients who are currently on stable medication regimens.

However, there may be reduced coverage or none at all for a small number of effective drugs. For example, the specific exclusions of benzodiazepines and opiates such as buprenorphine are of great concern. Oral benzodiazepines are listed on the World Health Organization's Essential Drugs List for

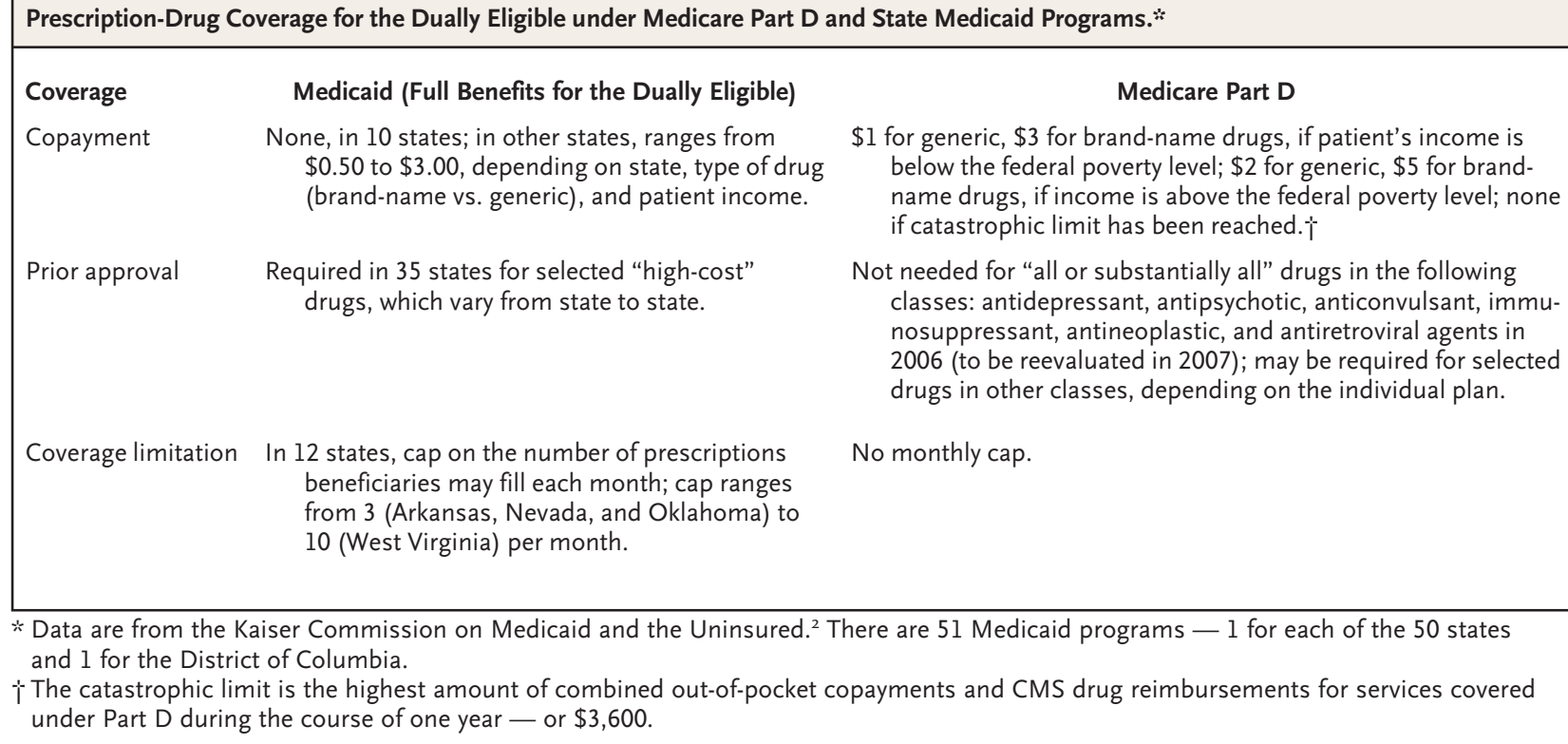

Coverage Medicaid (Full Benefits for the Dually Eligible)

Copayment None, in 10 states; in other states, ranges from $\$ 0.50$ to $\$ 3.00$, depending on state, type of drug (brand-name vs. generic), and patient income.

Prior approval

Required in 35 states for selected "high-cost" drugs, which vary from state to state.

Coverage limitation $\ln 12$ states, cap on the number of prescriptions beneficiaries may fill each month; cap ranges from 3 (Arkansas, Nevada, and Oklahoma) to 10 (West Virginia) per month.

\section{Medicare Part D}

$\$ 1$ for generic, $\$ 3$ for brand-name drugs, if patient's income is below the federal poverty level; $\$ 2$ for generic, $\$ 5$ for brandname drugs, if income is above the federal poverty level; none if catastrophic limit has been reached. $\dagger$

Not needed for "all or substantially all" drugs in the following classes: antidepressant, antipsychotic, anticonvulsant, immunosuppressant, antineoplastic, and antiretroviral agents in 2006 (to be reevaluated in 2007); may be required for selected drugs in other classes, depending on the individual plan.

No monthly cap.

* Data are from the Kaiser Commission on Medicaid and the Uninsured. ${ }^{2}$ There are 51 Medicaid programs -1 for each of the 50 states and 1 for the District of Columbia.

$\uparrow$ The catastrophic limit is the highest amount of combined out-of-pocket copayments and CMS drug reimbursements for services covered under Part D during the course of one year - or $\$ 3,600$. 
anxiety and sleep disorders and are also indicated for the shortterm management of bipolar disorders and for treatment of panic attacks that have been refractory to antidepressants. ${ }^{3}$ The loss of coverage may result in the abrupt cessation of benzodiazepine therapy in as many as 1.7 million long-term users, potentially leading to severe or even life-threatening withdrawal symptoms. ${ }^{4}$

To address this problem, Representatives Benjamin Cardin (D-Md.) and Jim Ramstad (R-Minn.) have filed legislation to cover benzodiazepines. If this bill is not passed, the CMS has indicated that states should cover drugs excluded by Medicare Part D if they are covering such drugs for other Medicaid enrollees. It is not yet clear, however, how many states will cover such drugs for dually eligible patients on January 1 .

Private Medicare drug plans, which will decide which medications are included in their formularies, are permitted to restrict coverage to two drugs per "class." The U.S. Pharmacopeia classifications have been criticized for being too broad, thus defining an inadequate number of classes; for example, all newer and older oral hypoglycemic agents constitute a single class. Medicare's acceptance of these classifications allows plans to restrict the total number of drugs covered, perhaps incorrectly assuming equivalence within a class. Aside from the designated classes in which therapeutic substitution is least appropriate, it is unclear how extensive the options will be overall.

Proposed plans vary in medication coverage, and many rely on utilization-management techniques. Dispensing of some agents may be allowed only after the failure of "preferred" agents or prior authorization for use of "nonpreferred" drugs. Moreover, "offlabel" prescribing is not reimbursable under Medicare, which may be relevant if prior authorization is required. To minimize adverse events, clinicians will need to carefully monitor chronically ill patients who are forced to switch to a new medication.

Research has demonstrated that policies that increase cost sharing for medications reduce the use of essential medicines such as thiazide diuretics, antidiabetes agents, and psychotropic agents, even as they reduce inappropriate drug use. Such policy changes may lead to negative health outcomes and increased use of emergency services and overall health care costs. $^{5}$

A number of steps could maximize the benefits of the MMA for the dually eligible. We believe that the transition period should be lengthened to at least one year, creating a long "crossover" period during which beneficiaries can continue to obtain their medication through Medicaid. The CMS should identify explicitly who is to coordinate this transition. Prescribers should be supported by state-led prescribing-education programs to improve their aware- ness of intraclass variation in the effectiveness and side effects of specific drugs and to ensure that required medication switches do not compromise safety. Finally, the CMS should commission rapid studies to examine the impact of formulary restrictions and changes in cost sharing on the use of essential medication and health outcomes and should modify policies that cause underuse of essential medications or deleterious health effects.

$\overline{\text { Dr. Elliott is a clinical senior lecturer at the }}$ University of Manchester, Manchester, United Kingdom, and a Commonwealth Fund Harkness Fellow from 2004 to 2005; Dr. Majumdar is an associate professor of medicine at the University of Alberta, Edmonton, Alta., Canada; and Dr. Gillick is an associate professor, and Dr. Soumerai a professor, of ambulatory care and prevention at Harvard Medical School and Harvard Pilgrim Health Care, Boston.

1. Centers for Medicare and Medicaid Services. Medicare dually eligible population in 2002. (Accessed December 8, 2005, at http:// www.medpac.gov/publications/congressional_ reports/Jun04DatabookSec2.pdf.)

2. Kaiser Commision on Medicaid and the Uninsured. Medicaid benefits: online database. Benefits by service: prescription drugs (October, 2004). Washington, D.C.: HenryJ. Kaiser Family Foundation, 2005. (Accessed December 8, 2005 at http://www.kff.org/ medicaid/benefits/service.jsp?gr=off\&nt= on \&so $=0 \& \operatorname{tg}=0 \& y r=2 \& c a t=5 \& s v=32$.)

3. Essential Medicines Library (EMLib). WHO model formulary: English edition 2004. Geneva: World Health Organization, 2005.

4. Bambauer KZ, Sabin JE, Soumerai SB. The exclusion of benzodiazepine coverage in Medicare: simple steps for avoiding a public health crisis. Psychiatr Serv 2005;56:1143-6. 5. Soumerai SB. Benefits and risks of increasing restrictions on access to costly drugs in Medicaid. Health Aff (Millwood) 2004;23(1):135-46. 